\title{
Probable E3 Ubiquitin-Protein Ligase MYCBP2
}

National Cancer Institute

\section{Source}

National Cancer Institute. Probable E3 Ubiquitin-Protein Ligase MYCBP2. NCI Thesaurus.

Code $C 88943$.

Probable E3 ubiquitin-protein ligase MYCBP2 (4640 aa, $510 \mathrm{kDa}$ ) is encoded by the human MYCBP2 gene. This protein may play a role in both the mediation of ubiquitination and the regulation of transcription. 